\title{
O MUSEU COMO LUGAR DE RESISTÊNCIA: MEMÓRIA E REPRESENTAÇÃO DE COMUNIDADES AFRICANAS E AFRODIASPÓRICAS
}

\section{Entrevista concedida por Marcelo Nascimento Bernardo da Cunha ${ }^{1}$ a Elizeu Clementino de Souza. ${ }^{2}$}

Elizeu Clementino de Souza (ECS): Marcelo, inicio por agradecer pela disponibilidade para realização da entrevista e que possa situar suas pesquisas e experiências com gestão de museu.

\section{Marcelo Nascimento Bernardo da Cunha} (MNBC): As minhas pesquisas, realizadas desde a minha graduação em Museologia, iniciada em 1986, e ao longo dos últimos 30 anos, dedicados à docência na Museologia, acabaram como uma certa confluência, não somente porque estou na cidade de Salvador, na Bahia, e acabaram me levando para reflexões so-

1 Professor associado III do Departamento de Museologia da Universidade Federal da Bahia (UFBA), membro do Programa de Pós-Graduação em Museologia (PPGMUSEU) da UFBA; do Programa Multidisciplinar de Estudos Étnicos e Africanos (POSAFRO) da UFBA; do Programa de Estudos Pós-Graduados em Museologia da Universidade Lusófona de Humanidades e Tecnologias (ULUSOFONA) em Lisboa. Coordenador do Grupo de Pesquisa Observatório da Museologia na Bahia. Coordenador do Museu Afro-Brasileiro da UFBA.

2 Pesquisador $1 \mathrm{C}$ do Conselho Nacional de Desenvolvimento Científico e Tecnológico (CNPq). Professor titular do Programa de Pós-Graduação em Educação e Contemporaneidade (PPGEduC) da Universidade do Estado da Bahia (UNEB). Coordenador do Grupo de Pesquisa (Auto)biografia, Formação e História Oral (GRAFHO) da UNEB. Pesquisador associado do Laboratorie Experice da Université de Paris 13-Paris 8. Tesoureiro da Associação Brasileira de Pesquisa (Auto) biográfica (BIOgraph). Membro do Conselho de Administração da Association Internationale des Histories de Vie en Formation et de La Recherche Biographique en Education (ASIHIVIF-RBE). Editor da Revista Brasileira de Educação (RBE) da Associação Nacional de Pós-Graduação e Pesquisa em Educação (ANPEd), Editor da Revista da FAEEBA e da Revista Brasileira de Pesquisa (Auto)biográfica (RBPAB). bre a questão da memória e representação de comunidades africanas e afrodiaspóricas. Ao longo desses anos, foram vários os produtos oriundos dessa pesquisa: uma dissertação de mestrado, ${ }^{3}$ uma tese ${ }^{4}$ e várias outras produções que se associaram ao fato de que, ao longo desses anos, durante mais de 15 anos, com intervalos, fui gestor do Museu Afro-Brasileiro da Universidade Federal da Bahia (UFBA), estando novamente à frente da sua gestão desde o ano de 2018.

Ao longo desse tempo, minhas reflexões estiveram relacionadas à questão da representação expográfica, em si, pensando nos acervos e estratégias de apresentação. Eu continuo com essa abordagem. 0 meu projeto de pesquisa atual ${ }^{5}$ configura-se em uma imersão nas reservas técnicas de museus da cidade de Salvador, identificando acervos relacionados diretamente ou indiretamente a esse universo e que estão lá, relegados ao abandono e invisibilidade. Mas, de um tempo para cá, eu comecei a pensar o corpo especificamente, porque me dei conta de que todas as questões que envolvem esse alheamento, esse silenciamento, esse discurso no negativo, sobre a cultura afro-brasileira, está sintetizado nas visões construídas sobre o corpo. Dizendo de outra forma, é esse corpo negro que vai fazer com

3 A Exposição como um Sistema de Informação: o Caso do Museu Afro-Brasileiro da Universidade Federal da Bahia. Mestrado em Ciência da Informação pelo Instituto de Ciência da Informação (ICI) da UFBA, em 1999.

4 Teatro de Memórias, Palco de esquecimentos: culturas africanas e das diásporas negras em exposições. Doutorado em História Social pela Pontificia Universidade Católica de São Paulo (PUC-SP), em 2006.

5 Museus: Velhos acervos e novas perspectivas. Construindo novos discursos a partir de antigas coleções. 
que essa cultura e essas manifestações sejam colocadas em segundo plano, na melhor hipótese, pois não é segundo plano, e sim a construção de um discurso negativo. É esse corpo que foi estigmatizado em discursos museológicos e, em certo sentido, ainda continua a ser. E quando penso nesse processo relacionado à construção de imagens a partir de corpos e memórias negras, efetivamente estou pensando em biografias e protagonismos negros anulados em processos patrimoniais.

(ECS): Como você tem pensado sobre processos de silenciamento e possiveis apagamentos relacionados à cultura afro-brasileira?

(MNBC): Então, tenho buscado refletir sobre esse processo na perspectiva histórica, realizando um apontamento sobre alguns momentos desse processo de construção de imagens, em um intervalo de mais de 200 anos. Recentemente acompanhamos pela mídia um evento bastante interessante que tenho usado para dar início a conversas sobre corpos negros e construção de imagens na perspectiva do patrimônio e espaços de memória. Esse ato aconteceu em um território que, no senso comum, é entendido como paradigma do que seja um museu, o Museu do Louvre, ${ }^{6}$ e o que deveria ter sido um evento comum, sem importância, como os vários que acontecem em museus contemporâneos, repercutiu em um debate intenso na mídia, envolvendo grupos de fãs e rodas de especialistas, refiro-me ao videoclipe filmado no museu, protagonizado pelo casal pop americano Beyoncé e Jay $Z$.

Ao assistir ao vídeo, já de partida temos uma imagem bastante emblemática, quando vemos o casal, seguramente na sala mais visitada do Museu, aquela em que se encontra a obra Monalisa.

Esse local está sempre lotado de gente e deve ser o mais visitado entre todos do Museu, e provavelmente a sala de museu mais visitada

6 Mais informações em: https://www.louvre.fr/en/. do mundo, onde milhares de pessoas acotovelam-se por dia para ver esta obra que se transformou, ela própria, em ícone pop das artes. ${ }^{7}$ Nesta primeira sequência do vídeo, ainda que seja dado destaque, por alguns segundos, ao quadro, chama nossa atenção o fato de que os dois encontram-se de costas para a obra. Considero muito emblemática e provocativa essa postura assumida por eles.

Figura 1 - Frame do vídeo Apshit.

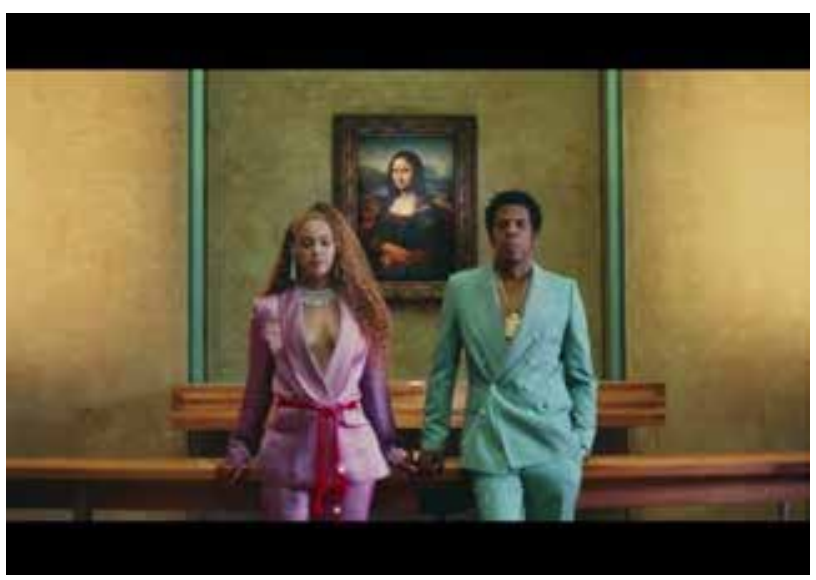

Fonte: https://i.ytimg.com/vi/kbMqWXnpXcA/hqdefault.jpg

Na sequência, tendo a escultura da Vitória da Samotrácia às costas, vemos o casal que observa um grupo de bailarinas em coreografia que se desenvolve na escadaria que leva até a famosa escultura. Esse grupo dança em vários ambientes tendo ao fundo obras de arte.

Figura 2 - Frame do vídeo Apshit.

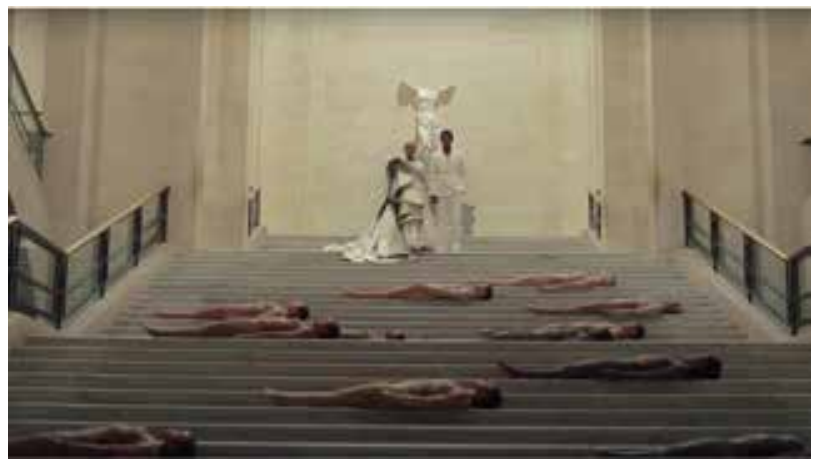

Fonte: https://www.francetvinfo.fr/image/75iuk5ty3-b239/1500/843/15291999.png

7 Em 2018, o Louvre esteve em primeiro lugar entre os museus do mundo, ultrapassando 10 milhões de visitantes. 
Figura 3 - Cartaz de divulgação do zoológico do Jardim da Aclimatação, no ano de 1922, em Paris.

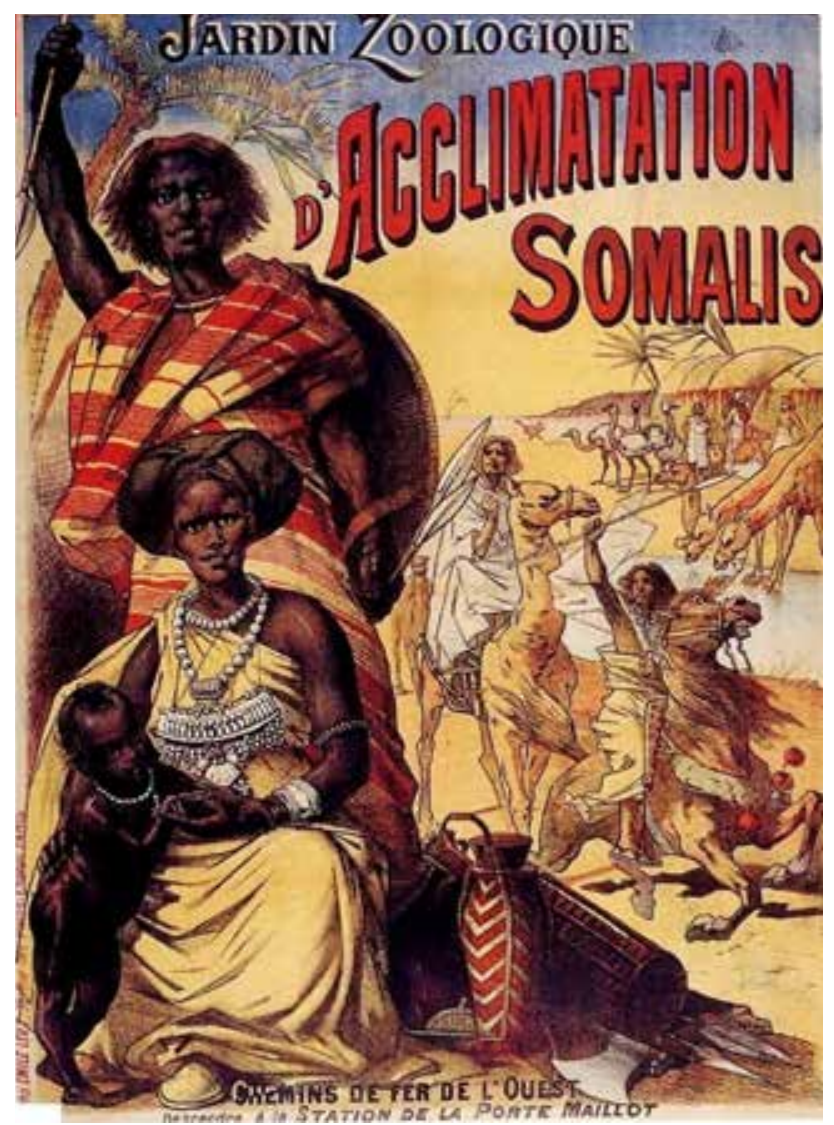

Fonte: http://hgsavinagiac.over-blog.com/article-314956 23.html

Tal é a tônica do vídeo, o espaço do museu e suas obras como suporte para a realização do clipe, sendo o destaque dado ao casal e dançarinos e dançarinas negros que participam do vídeo. Ao final da obra, percebemos que o que ocorreu ali não foi uma simples visita ao Louvre ou uma gravação de um vídeo, mas sim uma ocupação.

(ECS): Quais as repercussões e desdobramentos do vídeo para o campo de pesquisa e suas interfaces com a área acadêmica?

(MNBC): O vídeo provocou muita repercussão, gerando a produção de artigos acadêmicos e ensaios, mas um artigo publicado na página do jornal $O$ Estado de São Paulo, em 25 de junho de 2018, intitulado "Bacanal Narcisista no Louvre", me chamou a atenção. ${ }^{8}$ A autoria é de uma crítica brasileira, Sheila Leirner, que

8 Disponivel em: https://sheilaleirnerblog.wordpress. com/2018/06/25/bacanal-narcisista-no-louvre/. segundo informações da coluna, vive em Paris desde 1991. O seu texto revela uma reação enfurecida ao clipe, permeada de preconceitos e estigmas. ${ }^{9}$ Já na abertura do texto, ela explora o título a partir da perspectiva pejorativa do seu suposto significado e afirma, em uma interpretação semântica relacionada à animalização que "Apeshit (Fezes de Macaco), o título do novo clipe de Jay-Z e Beyoncé já diz tudo: a partir do hábito de macacos raivosos arremessarem suas próprias fezes no que odeiam, este nome significa nos humanos um comportamento parecido com o do macaco enfurecido".

Nesse trecho inicial, ela sinaliza o lugar de sua fala racista, construindo uma crítica que recorre a figuras semânticas relacionadas à animalização para tratar o vídeo realizado por um casal afro-americano. Em dado momento, percebemos que um dos pontos essenciais da sua crítica baseia-se no fato do suposto pouco valor atribuído pelo casal pop e seu grupo às consagradas obras da arte ocidental depositadas no museu. Seu texto trata com grande afronta o modo como essas pessoas portaramse no Louvre. Classificando a produção como "um mau momento brega que, infelizmente não vai durar como a Mona Lisa", ela segue em considerações sobre o pop, revelando seu incômodo e classificando o vídeo como "uma afronta, uma vingança política afro americana sobre a grande cultura".

Ao ver as imagens dessa performance ocorrida no Louvre, em 2018, passo e refletir sobre a presença - ou ausência - de corpos negros em espaços sacralizados de memória e arte, tão bem representados por esse museu para-

9 Ver textos críticos em resposta ao texto de Sheila Leirner: "Bacanal narcisista no Louvre" Um preto no Louvre incomoda muita gente... Portal Geledés https://www. geledes.org.br/bacanal-narcisista-no-louvre-um-preto-no-louvre-incomoda-muita-gente/; OLIVEIRA, Felipe de Souza. Bacanal Narcisista no Louvre: Racismo e Poder através da adjetivação em um post de Sheila Leirner no Jornal Estadão. Revista Investigações, Recife, v. 32, n. 2, p. 507-521, Dezembro/2019. Disponivel em: periodicos.ufpe.br/revistas/INV/article/view/241767. 
digmático e sobre a consequência desse processo para a construção biográfica coletiva da comunidade negra, no que diz respeito à sua relação com as artes consagradas e seus espaços de preservação. Dito de outro modo, sou provocado a refletir sobre o modo como corpos negros foram produzidos e reproduzidos no universo da preservação imagética e simbólica do patrimônio ocidental.

No caso específico do Louvre, desde a origem, somente em 2000 foi inaugurada uma exposição voltada para a abordagem "representação e apresentação de culturas não ocidentais". Não podemos esquecer que a arte do Egito está presente em exposição desde 1827, mas em uma perspectiva que coloca o Egito à parte do contexto africano como um todo, não sendo estabelecidos nexos com as culturas africanas relacionadas ao que denominamos tradicionalmente "África negra". Assim, demorou 207 anos, desde a criação do Museu, para que fosse apresentada uma exposição, na área chamada de Pavilhão das Sessões, com objetos de sistemas culturais africanos em destaque, mas ainda de uma forma bastante estetizada e com pouca discussão sobre o acervo em si e seus contextos culturais. A sala apresenta não somente elementos da África, mas também da América, Ásia e Oceania.

Tomando o Louvre como instituição que moldou formatos e modelos de musealização e referencial que influenciou outras instituições, ao buscar entender como se deu esse processo de negação da presença de corpos/culturas negras, materializados e representados pela produção de cultura material, podemos nos aproximar da forma como esse processo se deu no mundo dos museus tradicionais.

Nesse contexto, descobrimos que, em 1920, Felix Fenéon, escritor, crítico e colecionador de arte, realizou enquete com antropólogos, críticos de arte, galeristas e artistas, indagando se a arte africana deveria ser admitida no Lou- vre..$^{10}$ Não só a africana, mas o que ele chamava de "artes distantes". Ao analisar o material, vemos que as opiniões foram diversas. Houve desde quem achasse que efetivamente esta entrada já havia passado da hora, mas também quem afirmasse que essas manifestações artísticas não deveriam nunca entrar, porque não estariam no padrão esperado para compor o acervo do Louvre e que, para isso, existiriam outros espaços, como museus etnográficos, por exemplo.

(ECS): O corpo como espaço de interdição inscreve-se como espaço de poder-saber. Assim, como tem compreendido o corpo negro e suas formas múltiplas de manifestações no campo da Museologia?

(MNBC): Assim, é nessa perspectiva de pensar esse lugar e o status a ele atribuído em superioridade da produção artística africana é que eu acabo pensando nos corpos da Beyoncé e do Jay Z dentro do Louvre em 2018, e as reações provocadas. Nessa reflexão, me vem a imagem desse corpo classificado e ligado indiretamente, pela crítica citada da Sheila Leirner, a um corpo de animal, a um corpo animalizado. Nesse ponto, pensando nessa questão, não tenho como não voltar a um outro tema que tenho pesquisado, que compõe um dos capítulos da minha tese de doutorado, que são os chamados "zoológicos humanos".11 Um fenômeno de meados do século XIX, ocorrido na Europa e Estados Unidos, ligado aos freack shows, mas também aos zoológicos e museus, bem como a toda uma necessidade dessa Eu-

10 Enquête sur des arts lointains. Seront-ils admis au Louvre ? Bulletin de la vie artistique, 24, 25 e 26, 1920. Disponivel em: https://commons.wikimedia.org/wiki/ File:F\%C3\%A9n\%C3\%A9on_-_Iront-ils_au_Louvre_\%3F_ Enqu\%C3\%AAte_sur_les_arts_lointains,_Bulletin_de_ la_vie_artistique,_24,_25_et_26,_1920.djvu.

11 Ver BANCEL, Nicolas. BLANCHARD, Pascal. LEMAIRE, Sandrine. Os jardins zoológicos humanos. Le Monde Diplomatique - Brasil. Disponivel em: https://diplomatique.org.br/os-jardins-zoologicos-humanos; BOETSCH, Gilles. DEROO, Éric. LEMAIRE, Sandrine. BANCEL, Nicolas. Pascal BLANCHARD. Zoos humains: Au temps des exhibitions humaines. Paris : La Decouverte, 2004. 485p. 
ropa dita civilizada, civilizante e conquistadora do século XIX, com o objetivo de justificar o seu projeto de dominação e invasão de outros territórios, a partir da construção de um discurso, à época científico, reforçado na perspectiva de discurso científico popularizado.

Esses locais, para além da popularização de teorias científicas, vão se tornar um grande negócio, com o surgimento de empresários que vão começar a importar indivíduos para serem apresentados em suas exposições vivas. Esse é um processo muito complexo que vai dar origem, inclusive no território africano, a grupos que vão formar trupes teatrais e se colocar à disposição para participar dessas exibições. Sabemos que alguns realmente estabelecem contratos de trabalho, mas que, efetivamente, na "hora h", ficarão muito próximos do trabatho escravo. Esse é um processo que envolve negociação e que tem muitas facetas, incluindo processo de captura violenta.

Nesse contexto, então, esse corpo negro passa a ser um corpo exibido, e mais do que isso, aproveita-se, por exemplo, esse espaço do zoológico, para se estabelecer laboratórios de antropologia física onde vão se fazer medidas de craniometria e todas os exames relacionados às comprovações das hipóteses hierarquizadas e hierarquizantes da antropologia física e das teorias raciais da época.

Figura 4 - Cartão postal da Exposição de Angers (França), 1906 apresentando sessão de vacinação.

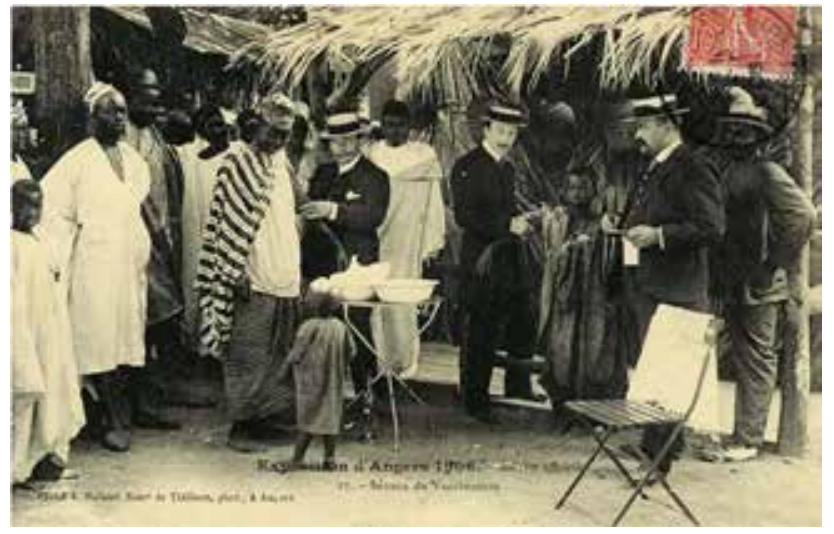

Fonte: https://www.unidivers.fr/zoos-humains-villagenegre-place-hoche-rennes/
(ECS): Ao tomar o corpo como território de contestação, como compreende e tem percebido montagem das exposições neste terreno contestado, híbrido, grotesco e de resistência?

(MNBC): Os ambientes montados têm um caráter expográfico extremamente forte. A ideia era recuperar e reproduzir ambiências de uma forma bastante detalhada. Os exemplos mais fortes e elaborados foram as exposições etnográficas no âmbito das exposições universais, industriais e coloniais. Em todas, vai ocorrer exibição de pessoas, sendo que as etnográficas coloniais são as que exploram mais fortemente essa perspectiva, com a apresentação de grupos das sociedades exploradas, com a intenção de mostrar as populações de territórios fornecedores de matérias-prima, com potencial a ser explorados como mão de obra e consumidores, apresentando sua população imensa, a ser civilizada.

Figura 5 - Fotografia reunindo personagens do freak show, na década de 1920.

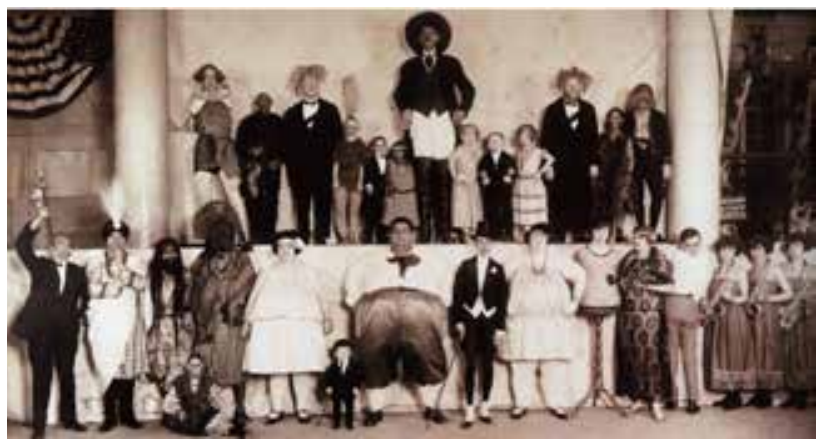

Fonte: https://allthatsinteresting.com/freak-show-members

E aqui novamente ao pensar a questão do corpo, vemos que nesses processos foi construído todo um discurso sobre o corpo do outro, a partir do contraste, a partir da polarização. É muito interessante observarmos fotografias em que podem ser vistos, em uma mesma cena, animais, além de indivíduos "extremos": um elefante, um grupo de anões, um homem muito alto e ainda um homem de estatura mediana. A ideia da composição desse discurso nas imagens que são construídas, seja nos car- 
tazes, exposições ou circos é exatamente a da contraposição. Quando era exposto um anão ao lado de um homem de dois metros e vinte, a contraposição acabava reforçando cada um dos corpos presentes na cena.

Nas imagens apresentadas, havia uma preocupação de ambiência muito grande, com a importação e criação de cenários, através de pinturas, utilização de objetos e indumentárias. Assim, imagens não só eram recriadas, mas também inventadas. Por exemplo, alguns grupos que nunca praticaram a nudez total ou parcial, ou que naquele momento já tivessem outros hábitos, poderiam ser apresentados seminus, porque a ideia da composição, fosse através de uma fotografia popularizada através de postal, ou em um ambiente de circo ou zoológico, era através da nudez confirmar o imaginário que relacionava tais grupos à incivilidade e à animalização.

Então, essas exposições serviam para confirmar o imaginário, mas o imaginário também servia para modular as representações. Não era só a questão racial que estava em jogo, mas a ideia de normalidade. E aí, todos os que fugissem dessa ideia, na perspectiva corporal, fossem albinos, anões, pessoas muito gordas, pessoas muito magras, considerados fora do padrão, seriam explorados como monstruoso.

(ECS): Poderia explicitar processos de estudo sobre o tema e relações com exposições?

(MNBC): Estudei mais detidamente uma dessas exposições, a que foi realizada na categoria de exposição colonial, em 1934, na cidade do Porto, em Portugal. Seu objetivo, como o de todas as outras realizadas por nações exploradoras colonialistas, era justificar projeto de exploração do continente africano e outros territórios, construindo um discurso que explicitasse a importância de Portugal em cuidar daqueles indivíduos que "precisavam ser civilizados", mas, para além disso, havia a perspectiva econômica voltada para atrair investimentos para o projeto colonial imperial português, atraindo mão de obra para um projeto apresentado como proveitoso para todos os envolvidos. Em 1940, Portugal realizou outra exposição, voltada para comemorar o chamado Mundo Português, não somente as suas colônias de então, tanto que o Brasil participou. Nessa exposição, havia um módulo colonial, mas a grande construção do seu discurso colonial, através de uma exposição se deu em 1934.

Tais exposições eram acompanhadas de várias atividades complementares. Em Porto, todos os dias havia divulgação de suas rotinas através de um jornal apoiador. Nas noticiais veiculadas, encontramos uma infinidade de imagens que exploravam contrastes, como a nudez incivilizada em contraste com a civilidade dos trajes que deveriam ser adotados por esses grupos. Também vão ser apresentados indivíduos que foram "adotados" pelo projeto português e que se tornaram bons cidadãos colaboradores do Império.

A ideia de expografia, de expografia viva, de diorama estava presente todo o tempo, não somente através dos corpos, mas também da cultura material desses grupos, que era explorada. Paralelo às exposições, havia sempre o que eles chamavam de Museu Colonial. Várias dessas exposições acabaram dando origem a museus fixos, nos locais em que eram realizadas, ocorrendo, também, o envio de objetos para compor acervos de instituições de outras localidades. Assim, percebemos que não eram exibições esvaziadas, não era uma ação de expor por expor, era um elemento de apoio ao projeto colonial e sua propaganda. Nesse sentido, paralelas à própria exposição ocorria uma série de atividades, como congressos para discutir agricultura colonial, educação colonial, formação de bases metropolitanas para trabalhar no projeto nos territórios explorados, entre outros temas. 
Chama a atenção como esse corpo negro, principalmente o corpo da mulher negra, era objetivado nas exposições, não havendo nenhum pudor na sua exibição. Aqui é preciso lembrar que estamos falando de 1934, e de uma Europa conservadora e moralista, em que havia um rígido código moral e ético em relação à exposição do corpo da mulher branca. No entanto, essa mulher negra tinha o seu corpo completamente explorado. E isso é perceptivel também no discurso, marcado pela animalização e sexualização. Ao lermos descrições sobre mulheres africanas expostas no Porto, vai ser comum encontrar termos como "olhar lascivo" para descrever o seu semblante.

Figura 6 - Postal de grupo da exposição do Porto.

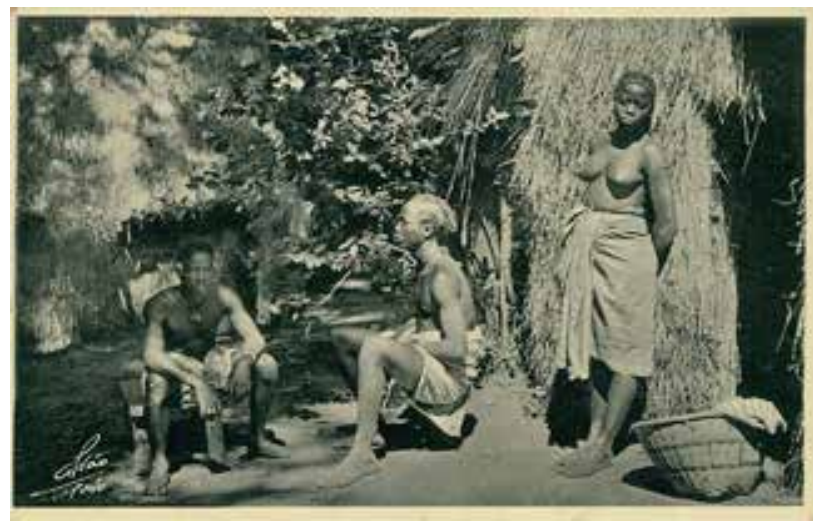

Fonte: http://www.commons.wikimedia.org

Durante a exposição do Porto, chegou a ser realizado um concurso para escolher entre as mulheres africanas qual seria a mulher mais bonita das colônias e, no momento em que eles estão divulgando o concurso, é muito forte o discurso de sexualização dessas mulheres que estão na exposição.

(ECS): O momento histórico que vivemos é marcado por ações de apagamento da memória e da cultura afro-brasileira, mas não só dela. Como tem analisado o contexto brasileiro atual, intervenções políticas e intervenções sobre o corpo e a cultura afro-brasileira?

(MNBC): No Brasil, nós também tivemos os nossos zoológicos e processos com lógicas semelhantes, que contribuíram para a construção de discursos negativos sobre corpos e grupos étnicos, como foi o caso na Bahia, do Museu Estácio de Lima, um museu etnográfico e antropólogo, que tem similares em diversas partes do Brasil, ecoando o que se realizava na Europa, sobretudo no século XIX.

Parte da coleção, que compunha um dos módulos do Estácio, estava relacionada com o processo iniciado em finais do século XIX, mas que se deu com mais força na primeira metade do século XX, de controle do Estado sobre as manifestações culturais e religiosas das comunidades afro no brasil. Para isso, foi criada toda uma estrutura, enfatizada no Estado Novo, com a criação de corporações de polícia, as chamadas "Delegacias de Costumes", voltadas para o controle não somente do universo afro, mas também de outros grupos, como por exemplo ciganos, orientais e italianos. Assim, qualquer elemento considerado destoante do que se entendia como o que deveria ser a nação brasileira e sua cultura acabava sendo controlado por essas delegacias. No caso afro -brasileiro, toda e qualquer pessoa relacionada ao universo religioso afro-brasileiro estava sob vigilância, e os templos religiosos eram controlados com a obrigatoriedade de registro e solicitação de autorização para qualquer ato ritual. Nesse mesmo contexto, eram controladas prostitutas e estabelecimentos relacionados ao exercício de sua profissão, como cabarés e bordéis.

Nesse período, foram realizadas uma série de ações relacionadas ao desenvolvimento de ideias relativas ao movimento higienista, baseadas na ideia de higienização e controle social, voltados para a mudança comportamental, rumo à República, que na perspectiva das classes dominantes, precisava afirmasse ao lado das principais repúblicas ditas civilizadas do mundo. Tal pensamento camuflava e alimentava a mentalidade racista nacional, 
sendo utilizada uma série de subterfúgios para o controle. Havia perseguição religiosa e cultural que se dava de forma indireta, então, sacerdotes e sacerdotisas eram enquadrados criminalmente com alegação, por exemplo, de exercício ilegal da profissão da medicina.

Sacerdotes e sacerdotisas do candomblé poderiam ser presos, por exemplo, sob a alegação de ter sequestrado alguém, pois o processo de iniciação, que implicava o recolhimento e isolamento, nem sempre era realizado com a conivência da família da pessoa iniciada, daí, muitas vezes, a própria família acabava procurando a delegacia, implicando criminalmente, sacerdote ou sacerdotisa, por conta dessas acusações.

Nesse processo de controle e perseguição, formou-se um acervo de objetos relacionados ao universo afro-brasileiro, que hoje se encontra espalhado pelo Brasil. Alguns depositados em coleções mais sistematizadas, expostos ou em reservas técnicas. Outros abandonados sem tratamento. Tais objetos eram recolhidos das comunidades de origem como prova do crime. Uma parte era destruída, outra poderia ir para estudiosos de institutos geográficos (por isso vários institutos geográficos pelo Brasil têm esse tipo de acervo) e também para faculdades de medicina, onde médicos pesquisadores estavam envolvidos com teorias da antropologia médica, higienismo e medicina legal, em voga no Brasil e suas academias desde meados do século XIX. Nesse contexto, na Faculdade de Medicina da Bahia, atual Faculdade de Medicina da UFBA, destacou-se o médico Nina Rodrigues em seus estudos relacionados à antropologia médica, voltada para o universo afro-brasileiro.

As faculdades de Medicina, isso é uma tradição que vem da França, têm na sua origem forte relação com a formação de coleções relacionadas à patologia, à anatomia e também à antropologia. A coleção Estácio de Lima tem origem em meados do século XX, na Escola de Medicina. Seu acervo não tem nada a ver, diretamente, com a coleção do Nina Rodrigues, que formou uma coleção que é relatada como museu, no final do século XIX, sobre a qual temos muito poucas referências e informações. No senso comum, e mesmo entre alguns pesquisadores, há a crença de que o atual acervo da Coleção Estácio contém o acervo do Nina, mas o que sabemos é que acervo do Nina foi destruído pelo incêndio ocorrido na Faculdade de Medicina em 1905. Mas o que podemos afirmar é que ideologicamente a coleção do Estácio tem relação com a coleção do Nina, mas na perspectiva daquilo que se pensava e se fazia nas escolas de medicina desde o século XIX. Além da coleção do Nina, há documentos que informam sobre a existência de outras coleções formadas por outros médicos pesquisadores, na Escola de Medicina da Bahia, em fins do século XIX e ao longo da primeira metade do XX.

A Coleção Estácio de Lima leva o nome do médico e pesquisador, sucessor de Nina Rodrigues nos estudos de antropologia médica e medicina legal na Faculdade da Bahia, que a partir de meados do século XX deu início à sua formação. Posteriormente, ela foi institucionalizada como museu, funcionando no prédio da Faculdade de Medicina do Terreiro de Jesus, sendo transferida, na década de 1970, para o complexo da Delegacia de Polícia Técnica, do governo do estado da Bahia, passando então ao âmbito do Departamento de Polícia Técnica, ainda que por convênio tenha sido mantida relação da coleção com a Faculdade de Medicina.

Nessa coleção, havia um módulo muito importante composto por objetos afro-religiosos, para além de objetos relacionados ao Cangaço - objeto de estudo do doutor Estácio de Lima -, contravenção penal (tráfico de drogas, crimes e fraudes contra a economia popular), deformações patológicas, antropologia indíge- 
na. Muitas pessoas acreditam que a totalidade dessas peças teria origem na perseguição aos terreiros de candomblé e isso fez com que, desde a década de 1960, tenha ocorrido movimentos para que esses objetos saíssem do museu. Esse processo se deu com avanços e recuos. A reivindicação para saída das peças era a sua origem marcada pela intolerância e violência, sendo esse um argumento mais do que justo para o deslocamento. No entanto, a dificuldade no enfrentamento legal da questão era que, apesar de a perseguição e violência do Estado serem fatos documentados pela imprensa e pelas memórias dos mais velhos, não era possivel aos requerentes comprovar documentalmente a origem de cada objeto.

Enfim, por decisão do governo do estado e como eco dos movimentos sociais, em 2010, as peças sacras foram retiradas do Estácio e encaminhadas para o Museu Afro-Brasileiro, momento em que passei a ser o curador dessa coleção. 0 restante do acervo ficou no Museu Estácio de Lima, que já não funcionava. Quando as peças foram higienizadas, foi percebido que uma parte considerável não tinha marcas de uso, enquanto outras tinham resíduos, como fragmentos de penas, marcas de sangue e uma série de outros elementos que fazem parte dos processos de renovação energética de tais objetos quando em contexto litúrgico ritual. A inexistência de marcas, em parte do acervo, acabou sendo uma evidência que de que algumas não tenham origem em contextos de terreiro, ou pelo menos de um contexto ritual.

(ECS): Que síntese você situa dessas experiências e quais contribuições emergem para o campo de pesquisa e formação no contexto da graduação e da pós-graduação, mas também sobre o tratamento de coleções?

(MNBC): Do contato específico com essa coleção e da problemática relativa à sua origem, o argumento que comecei a construir é de que não importava a origem das peças, e aqui, ao afirmar a não importância da origem, não estou minimizando ou negando a violência do Estado através da força policial, materializada pela perseguição e invasão de terreiros, ou negando o crime cometido contra as comunidades afro-brasileiras. Claro que essa origem importa, mas a minha argumentação pretende reforçar a percepção do absurdo da presença dessas peças no Estácio de Lima, no contexto expositivo no qual foram colocadas por anos, pois ainda que nenhuma das peças tivesse origem na posição intolerante do Estado, o problema inquestionável, que não exige nenhuma prova por parte da comunidade ofendida era o contexto da exposição, era a forma como essas peças eram exibidas em um contexto que trabalhava com o campo semântico da anomalia, da doença, da corrupção, além de outros índices negativos, ou seja, o problema não era apenas a origem. Assim, creio que, talvez, se a crítica ao contexto tivesse sido potencializada desde a origem do questionamento sobre as peças no museu, talvez tivesse sido mais fácil o convencimento sobre a necessidade da retirada dos objetos sagrados do Estácio, ou pelo menos a construção do discurso de combate à presença dos objetos naquele museu.

Mas, ao assumir a perspectiva de crítica ao contexto, agora não mais com o objetivo de retirada das peças, pois essas já estão depositadas no Mafro, em sistema de comodato, desde 2010, passei a ter um problema, relacionado à necessidade de reconstituição do contexto expositivo, pois além da quase inexistência de documentação sobre o acervo afro-religioso, eu não tinha acesso a nenhuma informação relativa ao restante do acervo e da configuração expográfica do antigo Estácio. Essa situação foi atenuada, pois, em 2013, foi realizada a terceira Bienal da Bahia, uma retomada das duas primeiras, realizadas na década de 1960, tendo a segunda sido interrompida pelo gol- 
pe de 1964. Por conta da terceira Bienal, eu fui procurado em 2012, porque os curadores queriam expor o acervo oriundo do Estácio, depositado no Mafro. Essa intenção não se concretizou, pois é nossa definição de curadoria que esse acervo deverá ser exposto, a partir de um projeto curatorial em curso, como fruto das pesquisas que estão sendo desenvolvidas pela equipe de curadoria e, portanto, não interessa, antes disso, a exibição das peças fora dessa perspectiva.

No entanto, ainda que tenhamos tomado essa decisão, passamos a dialogar com a equipe de curadoria, que reconhecia nosso conhecimento sobre o Estácio, ainda que com bastante lacunas. Por conta desse diálogo, enfim, tivemos acesso a todo o acervo restante e fragmentos de documentos que tinham ficado para trás. A partir desse acesso, ainda que de forma fragmentada, passei a ter uma ideia do que foi o antigo museu e a sua configuração, e é a partir dessas evidências que no momento damos andamento ao tratamento dessa coleção.

Por fim, o que concluo nessa trajetória de experiências profissionais em torno de memórias africanas e afrodiaspóricas, no inter- cruzamento de pesquisa, docência e curadoria museológicas, é que essas ações são marcadas pela perspectiva metodológica de tratamento de coleções a partir da visão e abordagem fragmentada de acervos e de constituições expográficas.

Logo, para dar conta da tarefa urgente e inadiável de reverter a construção negativa de narrativas, através de acervos, que refletem corpos e vidas, creio que é necessário articular três conceitos para a construção de novas narrativas sobre histórias e biografias relativas a corpos negros, e aqui me refiro tanto a biografias de indivíduos e seus corpos, quanto a biografias das coleções e instituições. Tais conceitos são: fragmentação, ficção e poética e ainda estão em construção e amadurecimento nas minhas elaborações teóricas e processuais. A partir dessa minha percepção, acredito que eles precisam nortear nossas práticas. Penso que para além da compreensão de coleções, acervos e instituições, eles podem nos ajudar a revisar narrativas patrimoniais cristalizadas sobre corpos, memórias e suas biografias, contribuindo para desconstruir equívocos e preconceitos, propondo novos discursos e práticas. 